\title{
Research on evaluation indicators system of operation performance for desulfurization denitrification and dedusting equipment in key industries
}

\author{
Huang Jin ${ }^{1, *}$, Lin Ling ${ }^{1}$, Gao Xiang ${ }^{2}$, Zhu Tingyu ${ }^{3}$, Wu Xuecheng ${ }^{2}$, Fu Zhiming ${ }^{2}$, Zhang Xiaoxin ${ }^{1}$, Guo Yangyang ${ }^{3}$ Yan \\ $\mathrm{Xiamiao}^{3}$ \\ ${ }^{1}$ China National Institute of Standardization, Beijing 100191, China \\ ${ }^{2}$ The Institute for Thermal Power Engineering (ITPE) of Zhejiang University, \\ ${ }^{3}$ Institute of Process Engineering, Chinese Academy of Sciences
}

\begin{abstract}
As the situation of air pollutants control is more severe and the policy of energy-saving and emission reduction related industries become stricter at current time, it's urgent to carry out operation performance assessment work for flue gas desulfurization denitrification and dedusting equipment. This article analyses the current operation situation of the equipment of air pollutants emission and control in thermal power and steel industries in China, which shows the necessity and the urgency of a series of national technical specifications of operation performance assessment for flue gas desulfurization denitrification and dedusting equipment in key industries. Furthermore, the paper highlights the building of operation performance evaluation indicators system for coal-fired flue gas desulfurization denitrification equipment and dust collector for sintering flue gas from iron and steel industries, and the qualitative assessment requirements and the quantitative evaluation indicators, which could promote the construction of operation effectiveness assessment mechanism for air pollutants control equipment of key industries in China and accelerate the reliability and the effectiveness of the equipment operating in China by standardization.
\end{abstract}

\section{Analysis of Current Situation of Air Pollutants Emission and Control Equipment Operation in China Thermal Power and Steel Industries}

In recent years, along with the further pushing China's industrialization and urbanization, fossil energy utilization and resource consumption increase continuously, and the following results are further deteriorated air pollutants situation, continued intensified regional air pollutants, and multiple pollutant emissions that are listed in top position in the world. According to the Environmental Statistics Annual Report in 2012, China's SO2, NOx and smoke (powder) dust emissions were 21.176 million tons, 23.378 million tons and 12.343 million tons separately, of which $90.3 \%$ of SO2, $70.9 \%$ of NOx, and $83.4 \%$ of smoke dust came from thermal power, iron and steel, building materials and non-ferrous metal, etc. industrial emissions.

\subsection{Thermal power industry}

By the end of 2012, the national installed capacity of power generation reached 1.14 billion kilowatts (the thermal power accounted for $71.5 \%$ ); in 2012, the total coal consumption of power generation in the power industry was about 1.855 billion tons. In 2012, China's thermal power industry discharged 8.83 million tons of sulfur dioxide, 9.48 million tons of nitrogen oxides and 1.51 million tons of smoke dust, accounting for $41.7 \%$, $40.6 \%$ and $12.2 \%$ of the total national emissions, respectively. By the end of 2012, a total of 4,659 coalfired flue gas desulfurization units had been put into operation in China, with a total installed capacity of 718 million kilowatts (about 95\% of coal-fired power generation installed capacity). There were 548 coal-fired flue gas denitrification units with installed capacity of 226 million kilowatts $(30 \%$ of coal-fired installed capacity). Electrostatic precipitator is still the main dust collector in China's thermal power industry, accounting for about $90 \%$ in market. The bag filter (including the electric bag composite dust collector) has made significant progress and its technical level of fiber, filter material, accessories and automatic control are also developed to a certain degree, and its market share is $10 \%$. New technologies such as wet electrostatic precipitator, mobile plate electrostatic precipitator and low temperature electrostatic precipitator have been developed and applied. In July 2014, the Ministry of Environmental Protection [2014] No. 48 document published the National List of Desulfurization Facilities for Coal-fired Units, with a total of 4,467 coal-fired

\footnotetext{
* Corresponding author: huangjin@enis.gov.cn
} 
desulfurization units and a total installed capacity of 750 million kilowatts in China.

\subsection{Steel industry}

In 2012, the output of crude steel was 771 million tons, accounting for $46.3 \%$ of the world. The ferrous metal smelting and rolling processing industry consumed about $16.92 \%$ of the country's energy, and the emissions of $\mathrm{SO} 2$, NOx and smoke (powder) dust in ferrous industry were 2.406 million tons, 972,000 tons and 1.813 million tons respectively, accounting for $11.4 \%, 4.2 \%$ and $14.7 \%$ of the total national emissions, respectively. According to statistics in 2012, there were more than 1,240 steel sintering machines of various sizes and 389 desulfurization facilities for sintering machines, accounting for $1 / 3$ of the total number of sintering machines in China. And there were $2 / 3$ sintering machine not desulfurized. The on-building sintering machine and existed ones couldn't work synchronously. It's about $2 / 3$ couldn't operate normally, and the desulfurization efficiency is low: less than $1 / 2$ of the designed value. In July 2014, the Ministry of Environmental Protection announced the National List of Desulfurization Facilities for Iron and Steel Sintering Machines, The number of desulfurization facilities for national sintering machines reached 526, and the synchronous operation rate and desulfurization efficiency are still not optimistic. $80 \%$ of the domestic sintering machines apply electrostatic precipitators. The concentration of particulate matter was $50 \sim 100 \mathrm{mg} / \mathrm{m} 3$, which is much higher than that (it was $20 \mathrm{mg} / \mathrm{m} 3$ ) in developed countries.

\section{Standardize and improve the operation level of China's air pollutants control equipment by standardization, and support the implement of energy conservation and environmental protection related policies}

\subsection{Policies related to energy conservation and environmental protection is introduced continuously}

Since the Twelfth Five-Year Plan released, China has successively introduced a series of laws, regulations and policies to promote the control of flue gas sulfur dioxide, nitrogen oxides and smoke dust in key industries, and accelerated the construction of flue gas desulfurization denitrification and dedusting equipments for coal and steel industries. It has made some achievements in the prevention and control of sulfur dioxide, nitrogen oxides and smoke dust in China. In 2010, the Ministry of Environmental Protection promulgated the Technical Policy for the Prevention and Control of Nitrogen Oxides in Thermal Power Plants. In May 2010, Departments, including the Ministry of Environmental Protection, the National Development and Reform Commission, the Ministry of Science and Technology, and the Ministry of Industry and Information Technology in China, jointly issued the Guiding Opinions on Promoting Air Pollutant Joint Prevention and Control Work to Improve Regional Air Quality, which clearly proposes to boost the emission reduction of sulfur dioxide and nitrogen oxides and strictly control the emissions of coal-fired pollutants. In August 2012, the State Council issued the Twelfth Five-Year Plan for Energy Conservation and Emission Reduction with number [2012] No. 40, stating that: "In 2015, the total amount of sulfur dioxide emissions in China was controlled at 20.864 million tons that has a reduction of $8 \%$ comparing with 22.678 million tons in 2010 . The national total emission of nitrogen oxides is controlled at 20.462 million tons, which is $10 \%$ lower than the 12.376 million tons in 2010. It calls for the overall goal of the steel industry to reduce sulfur dioxide emissions by $27 \%$ comparing with 2012 emission amount. On September 12, 2013, the State Council issued the Air Pollutants Prevention and Control Action Plan which clarified ten specific measures, and the implement regulations were issued regionally. In 2014, the State Council successively issued the 2014-2015 Energy Conservation and Emission Reduction Low Carbon Development Action Plan (National Development Office [2014] No. 23) and opinions on Accelerating the Development of Energy Conservation and Environmental Protection Industry (National Development [2013] No. 30) and other important documents. The above important policy documents have put forward new and higher requirements for the current air pollutants prevention technology, equipment, engineering and standardization work.

\subsection{Technical standards system needs to be constantly improved}

Relevant emission standards have also been introduced to support the implementation of energy conservation and environmental protection related policies. GB 13223-2011 Air Pollutant Emission Standards for Thermal Power Plants promulgated in September 2011, that further severely restricted the emission standards of sulfur dioxide in China to $100 \mathrm{mg} / \mathrm{m} 3$, and the emission standards of sulfur dioxide and nitrogen oxides in key regions are $50 \mathrm{mg} / \mathrm{m}^{3}$ and $100 \mathrm{mg} / \mathrm{m}^{3}$. In July 2012, GB 28662-2012 Emission Standard of Air Pollutants for Sintering and Pelletizing of Iron and Steel Industry was officially released, stipulating that the emission limit of new sintering machine flue gas $\mathrm{SO} 2$ is $200 \mathrm{mg} / \mathrm{m} 3$, of which Beijing-Tianjin-Hebei, Yangtze river delta and Pearl river delta are special emission limits of air pollutants with required emission limit of SO2 180 $\mathrm{mg} / \mathrm{m} 3$; for existing enterprises, the emission limit of atmospheric particulate is $80 \mathrm{mg} / \mathrm{m} 3$, for all new enterprises from 2015, the company limit is $50 \mathrm{mg} / \mathrm{m} 3$, while the special limit region is $40 \mathrm{mg} / \mathrm{m} 3$. In 2014, China issued the latest Boiler Air Pollutants Emission Standard, which further restricted the emission indicators of industrial boilers. 
At present, China has established and implemented a series of relevant national and industry standards for coal-fired flue gas desulfurization denitrification and dedusting, such as: GB/T 19229.1-2008 Coal-fired flue gas desulfurization equipment Part 1 Gas-wet Desulfurization Equipment", GB/T 19229.2-2011 Coalfired flue gas desulfurization equipment Part 2: Coalfired Flue Gas Dry/Semi-dry Desulfurization Equipment, GB/T 19229.3-2012 Coal-fired Flue Gas Desulfurization Equipment Part 3: Coal-fired Flue Gas Seawater Desulfurization Equipment, GB/T 21509-2008 Coalfired Flue Gas Denitrification Technology Equipment, GB/T 21508-2008 Coal-fired Flue Gas Desulfurization Equipment Performance Test Method, HJ 2001-2010 Technical Specification for Flue Gas Desulfurization in Thermal Power Plants, DL/T 986-2005 Technical Specifications for Wet Limestone Gypsum Flue Gas Desulfurization, DL/T 998-2006 Performance Test Code for Wet Flue Gas Desulfurization Unit Performance Acceptance Test Specification, HJ562-2010 Selective Catalytic Reduction Method for Technical Specifications of Flue Gas denitrification Engineering in Thermal Power Plants, HJ 563-2010 Engineering Technical Specifications of Flue Gas-Selective Non-Catalytic Reduction Denitrification for Thermal Power Plants, etc.; important national standards of dust collector in China mainly include: GB/T6719 -2009 Technical Requirements for Bag Dust Collectors, GB/T 139312015 Test Methods for Performance of Electrostatic Precipitators (revision complete soon) and GB/T278692011 Electrostatic-fabric integrated precipitator, etc., as well as steel industry related standard HJ435-2008 Technical Specifications for Dust collector Engineering in the Iron and Steel Industry. The above standards have played an important role in regulating the quality of desulfurization denitrification and dedusting technologies, equipment and engineering in key industries. For all that, the standards for evaluating the operational performance of coal-fired flue gas and steel sintering flue gas desulfurization denitrification and dedusting equipment have not been followed up in a timely manner; on the other hand, China's technical and maintenance specifications include basic requirements of operation and maintenance for related facilities, but the environmental performance requirements, technical and economic performance, production management and main equipment conditions of the flue gas treatment facilities were not systematically standardized. In view of this, it is urgent to establish national standards for the operation performance assessment of coal-fired flue gas and steel sintering flue gas desulfurization denitrification and dedusting equipments, so as to develop the operation performance assessment of China's air pollutants control equipments to ensure the safety, steady and reliable operation, and to standardize and improve the operational efficiency and management level of China's air pollutants control equipment by standardization.

\section{The general thought for the technical requirements of national standard series for the assessment of the}

\section{operation efficiency of flue gas desulfurization denitrification and dedusting equipment in key industries}

In the field of air pollutants control environmental protection equipment, China has initially formed a relatively complete standard system, mainly including basic standards, testing method standards, technical and product standards and management assessment standards. Specifications on evaluation indicators system of operation performance for desulfurization denitrification and dedusting equipment in key industries belong to the management assessment standard. According to the toplevel design of the sub-system standard in the early of twelfth Five-Year Plan, the coal-fired flue gas desulfurization and denitrification equipment in thermal power plants and the steel sintering flue gas desulfurization and dedusting equipment were selected as the development targets of the series of standards to take the lead in establish relevant national standards. To this end, the National Standardization Management Committee's second batch of national standards revision plan in 2012 (National Standards Committee Comprehensive [2012] No. 92 document) approved three standard establishments, including the Technical Requirements of operation performance assessment for coal-fired flue gas desulfurization equipment (20121487-T-303), Technical Requirements of Operation Performance Assessment for Coal-fired Flue gas Denitrification Equipment (2012-1489-T-303) and Performance Assessment of the Desulfurization and Dust Collector for Sintering Flue Gas from Iron and Steel Industry (20121484-T-303). The National Environmental Protection Product Standardization Technical Committee (SAC/TC275) organized relevant enterprises, research institutes, universities, industry associations and testing institutions to jointly develop the three standards.

\subsection{Standard compilation principle}

Standards of flue gas desulfurization denitrification and dedusting equipments of different industries can draw up their own national standards for the assessment of the operational efficiency of flue gas desulfurization denitrification and dedusting equipment according to the characteristics of their own air pollutants control. It is necessary to unify the format, framework content and core technical requirements between the standards in this series. The assessment technical requirements and evaluation indicator system should be scientific, reasonable and operable.

The technical requirements for the the operation performance evaluation indicators of flue gas desulfurization denitrification and dedusting equipment in various industries should meet requirements such as comprehensive, streamlined and focused, from simple to complex, scientific and reasonable, and operability.

The principle of combining quantitative and qualitative, third-party testing and on-site inspection should be adopted. Qualitative indicators should be easy 
to verify, quantitative indicators should be measurable. And with the advancement of science and technology and industrial development, quantitative and qualitative evaluation indicators will continue to expand.

The technical requirements for operation performance assessment of flue gas desulfurization denitrification and dedusting equipment in key industries should fully consider the requirements of national environmental protection laws, regulations, policies and standards within a certain period of time, including relevant environmental protection industrial policies, resources and energy development and utilization and conservation policy, ecological construction and air pollutants prevention and environmental protection policies, as well as demonstration and promotion of air pollutants control technology and equipment, restrictions and elimination policies. The operation performance of desulfurization denitrification and dedusting equipment should be assessed scientifically, objectively, fairly and justly.

\subsection{Standard preparation}

The preparation of technical requirements and evaluation indicators system for the operation performance assessment of flue gas desulfurization denitrification and dedusting equipment in various industries shall start from investigating and combing the actual operation status, existing problems, operating equipment and testing method standards of flue gas desulfurization denitrification and dedusting equipments in various industries, and mature and reliable technology of desulfurization denitrification and dedusting and examples of results at home and abroad to determine the key selection direction of evaluation indicators;

The technical requirements for the operation performance assessment of flue gas desulfurization denitrification and dedusting equipment in various industries should adopt the first and second level evaluation indicators. The first-level indicators should include environmental performance assessment, resource and energy consumption assessment, technical and economic performance assessment, operational management assessment and equipment condition assessment. In order to achieve clean production and recycling economy in thermal power and steel industry, and meet environmental and economic benefits, the environmental performance requirements should be considered primarily, and then environmental goal could be achieved by the most economical manner, including technical economy and resource energy consumption indicators. Production management indicators and major equipment performance indicators are the ones for measuring the management status of enterprises and the operation level of environmental protection equipment, but the proportion should be less than environmental performance, technical and economic indicators, and resources and energy resource consumption indicators. The secondary evaluation indicators can be set according to the characteristics of different industries, and the weights of the indicators are determined according to the importance of each evaluation indicator.

The indicator data required for the technical requirements of operation performance evaluation indicators of flue gas desulfurization denitrification and dedusting equipment in various industries can be obtained by combining the statistical report data with the third-party test data. Provide clearly specifications for the test methods, test principles and data collection and calculation of the evaluation indicators.

\section{Construction of technical indicator system for operation performance assessment of flue gas desulfurization denitrification and dedusting in thermal power and iron and steel industry}

Technical indicator system for operation performance assessment of flue gas desulfurization denitrification and dedusting in thermal power and iron and steel industry consists of qualitative assessment requirements and quantitative evaluation indicator requirements.

\subsection{Qualitative assessment requirements}

The operation performance assessment of coal-fired flue gas desulfurization and denitrification equipment and the on-site inspection shall be carried out after the $168 \mathrm{~h}$ operation of the newly built, while modified (expanded) flue gas desulfurization equipment has been transferred for at least 6 months; The designed coal type shall be used during the inspection, test and assessment process, or use the ones as close as possible to the designed coal type; the flue gas desulfurization and denitrification equipment should be in stable operation, and the load adaptability test should be carried out for not less than 7 days. And it should be carried out twice at intervals of not less than 30 days, including at least the full load of the unit and $75 \%$ unit load.

The on-site inspection of the operation performance assessment of coal-fired flue gas desulfurization equipment shall comply with the requirements of $\mathrm{GB} / \mathrm{T}$ 16157, GB/T 21508, and DL/T 414.etc. The performance test of coal-fired flue gas denitrification equipment shall be carried out in accordance with the requirements of DL/T260, DL/T414.etc. The test results shall be compared with the results of the online monitoring system of flue gas.

The testing items of coal-fired flue gas desulfurization equipment shall include: flue gas flow rate, $\mathrm{SO} 2$ concentration, oxygen $(\mathrm{O} 2)$ concentration, flue gas flow, smoke (powder) dust content, flue gas density, and moisture content at import and outlet of coal-fired flue gas desulfurization equipment system; droplet concentration (wet method), sulfur trioxide concentration (SO3), mercury $(\mathrm{Hg})$ concentration, other gaseous pollutants concentrations, and system resistance and atmospheric pressure in the outlet flue gas.

The testing items of coal-fired flue gas denitrification equipment shall include: flue gas flow rate, NOx 
concentration, $\mathrm{SO} 2$ concentration, $\mathrm{O} 2$ concentration, flue gas flow, moisture content, dynamic pressure, static pressure, flue gas temperature, etc. at the inlet and outlet of the coal-fired flue gas denitrification equipment system; detection of system sulfur trioxide (SO3) concentration, ammonia slip rate; and system resistance, atmospheric pressure and catalyst performance, ammonia leakage, etc.

The performance and activity detection and assessment of coal-fired flue gas denitrification catalysts shall comply with the requirements of DL/T 1286. The storage and harmless treatment of waste catalysts shall comply with the requirements of GB 18597.

The noise detection at the boundary of the coal-fired flue gas desulfurization and denitrification equipment system shall comply with the requirements of GB12348. The noise detection of desulfurization and denitrification fans shall comply with the requirements of GB/T 2888 and $\mathrm{JB} / \mathrm{T}$ 8690. Other equipment noise should be measured at $1.0 \mathrm{~m}$ from the noise source.

The main project of iron and steel sintering should be synchronized to build a complete steel sintering flue gas desulfurization and dedusting equipment. In addition to the design requirements, the $\mathrm{SO} 2$ concentration and Particulate concentration after treatment should also meet the requirements of GB 28662 or local discharge standards.

The operation, repair and maintenance of iron and steel sintering flue gas desulfurization and dedusting equipment shall comply with the technical requirements of HJ 2040.

The discharge of desulfurization wastewater from steel sintering flue gas desulfurization and dedusting equipment shall be carried out in accordance with GB 8978 and the local sewage discharge standard. Desulfurization equipment should have an independent sewage treatment system, which can be discharged after treatment or meet the conditions of sewage network.

The storage and disposal of desulfurization solid waste in steel sintering flue gas desulfurization and dedusting equipment shall comply with the technical requirements of GB 18599.

The noise at the boundary of the iron and steel sintering flue gas desulfurization and dedusting equipment shall comply with the requirements of GB 12348 , and the noise of the fan shall comply with the requirements of $\mathrm{JB} / \mathrm{T} 8690$.

Enterprises that use and operate coal-fired flue gas and steel sintering flue gas desulfurization denitrification and dedusting equipments should establish a unified management system and management system, including quality management, environmental management, occupational health and safety management, and energy management system.

\subsection{Quantitative evaluation indicators system}

The quantitative evaluation indicators system for the operation performance assessment of coal-fired flue gas desulfurization and denitrification equipments and steel sintering flue gas desulfurization and dedusting equipments are shown in Table 1.

\section{Assessment method}

The assessment results of the operation performance of coal-fired flue gas desulfurization and denitrification equipment can be divided into three levels: "excellent", "good" and "general". Firstly, the total score and the appropriate weight value of the first-level evaluation indicator should be given respectively; then, the evaluation indicators selected in Table 1 can be combined with the requirements of each performance indicator according to relevant national standards and industry standards, combined with the production statistics reports of the user enterprises and on-site detection data to determine the standard scores of each grading of each secondary evaluation indicator; Finally, apply the single assessment and comprehensive assessment methods to calculate and comprehensively evaluate the measured values, and then calculate the comprehensive assessment score.

The assessment results of the operation performance of iron and steel sintering flue gas desulfurization and dedusting equipment can also be divided into three levels of "excellent", "good" and "general". The assessment objects can be divided into wet and semi-dry/dry flue gas desulfurization processes. Combined assessment is performed corresponding to an electrostatic precipitator or a bag filter. The assessment method can be evaluated according to the importance of each indicator by using the methods of primary and secondary weighting, standardization and total score.

\section{Conclusion}

The emission standards of air pollutants in China's thermal power and steel industries are becoming stricter, while the operation performance of pollutant control equipment are not scientifically and effectively evaluated. Policies related to energy conservation and environmental protection has been continuously introduced, and the technical standard system needs to be continuously improved. The assessment criteria for the operation performance of coal-fired flue gas and steel sintering flue gas desulfurization denitrification and dedusting equipment must be followed up in time.

The development of technical standards for operation performance assessment of air pollutants control equipment in thermal power and steel industry should fully consider the existing laws, regulations, policies and standards; the establishment of evaluation indicators system should be scientific and reasonable; the selection of evaluation indicators should take into account the environmental impact effects, resources, energy consumption, technical and economic performance, production management and the status of major equipment, etc., reflecting priority and focus while combining the operational characteristics of the equipment; the assessment method and assessment workflow should be scientific, objective, fair and just. 
Table1. Quantitative evaluation indicators system for operation performance of coal-fired flue gas desulfurization and denitrification equipment and steel sintering flue gas desulfurization and dedusting equipment

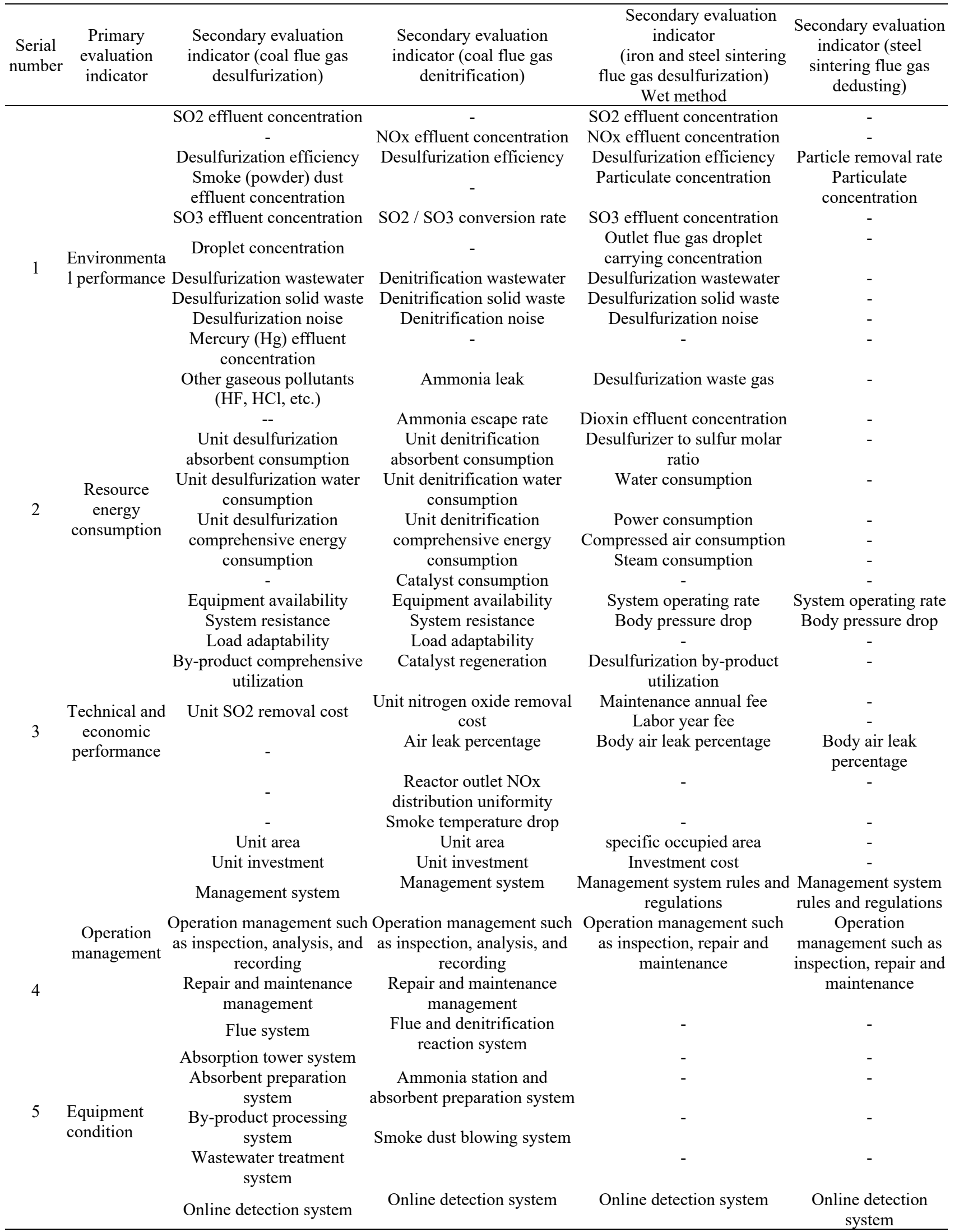




\section{References}

1. A. Mecke, I. Lee, J.R. Baker jr., M.M. Banaszak Holl, B.G. Orr, Eur. Phys. J. E 14, 7 (2004)

2. L Biao, H, G Xiang, W Xiuteng, W Xuecheng, C Yu. China Standardization, 5(2014).

3. GB/T 34340-2017 Technical requirements of operation performance assessment for coal-fired flue gas denitration installation.

4. GB/T34605-2017 Technical requirements of operation performance assessment for coal-fired flue gas desulfurization installation.

5. GB/T34607-2017 Performance Assessment of the Desulfurization Equipment and Dust Collector for Sintering Flue Gas from Iron and Steel Industry. 